\title{
Ideology: A Brief Guide
}

by John Lye, Copyright 1997

Ideology is a term developed in the Marxist tradition to talk about how cultures are structured in ways that enable the group holding power to have the maximum control with the minimum of conflict. This is not a matter of groups deliberately planning to oppress people or alter their consciousness (although this can happen), but rather a matter of how the dominant institutions in society work through values, conceptions of the world, and symbol systems, in order to legitimize the current order. Briefly, this legitimization is managed through the widespread teaching (the social adoption) of ideas about the way things are, how the world 'really' works and should work. These ideas (often embedded in symbols and cultural practices) orient people's thinking in such a way that they accept the current way of doing things, the current sense of what is 'natural,' and the current understanding of their roles in society. This socialization process, the shaping of our cognitive and affective interpretations of our social world, is called, by Gramsci, "hegemony;" it is carried out, Althusser writes, by the state ideological apparatuses -- by the churches, the schools, the family, and through cultural forms (such as literature, rock music, advertising, sitcoms, etc.)

While the concept of ideology is most generally associated with power relations, we have to keep from being too simplistic. Power is not a unitary force or phenomenon, nor an exclusively 'political' phenomenon. Power and power relations are woven throughout all our practices and ideas -- power is exercised in every relationship, group, and social practice, and it is not necessarily detrimental (what if a mother decided she did not want to operate in a power relationship to her newborn?). On the other hand, one must not forget that social order relies, in varying degrees, but ultimately, on the ability of one person or group to coerce another person or group, and that the basis of Law, however rationalized, is the authorized use of force.

Some conceptions of ideology de-emphasize the power aspect and see ideology as the structure of assumptions which form the imaginative world of groups. Ideology, writes Althusser, is "a representation of the imaginary relation of individuals to the real condition of existence." Further, Althusser writes, ideology creates us as persons: it "hails" us, calls us into being.

According to Marx, ideology naturalizes, it historicizes, and it eternalizes. That is, 
1. Ideological structures appear to be natural, "according to the order of things" (naturalization).

2. Ideological structures appear to be the logical conclusion to an historical development (historicization).

3. There is an assumption that now that this (natural) state of affairs has been reached, things will be that way, barring regression (eternalization).

\section{Structuralism}

Deconstruction is a poststructuralist theory, based largely but not exclusively on the writings of the Paris-based Jacques Derrida. It is in the first instance a philosophical theory and a theory directed towards the (re)reading of philosophical writings. Its impact on literature, mediated in North America largely through the influences of theorists at Yale University, is based in part on the fact that deconstruction sees all writing as a complex historical, cultural process rooted in the relations of texts to each other and in the institutions and conventions of writing, in part on the sophistication and intensity of its sense that human knowledge is not as controllable or as cogent as Western thought would have it and that language operates in subtle and often contradictory ways, so that certainty will always elude us. Structuralist groundworks

Reality as we understand it is constructed of certain deep structural principles or organizations which may be configured differently on the level of experienced life, as we both operate and interpet them differently. Language, for instance, is compose of basic resources (langue) from which individual instances of its use are drawn (parole); cultures are formed through basic relations of economic production (the Marxist conception of the 'base'), but these may appear differently as cultures (economies, in the economic and more general sense) configure their ideas and arrangements (the 'superstructure'). The idea is that there are basic structures which are operationalized according to certain transformative rules in relation to the particulars of specific situations.

There is no unmediated knowledge of 'reality': knowledge is symbolic; what we 'know' are signs; signs gain their meaning from their distinction from other signs. Therefore there is no knowledge of 'reality', but only of symbolized, constructed experience. Our 'knowing of our experience' is itself then mediated knowing, which is the only thing knowing can be. There is no 'pure' knowledge of reality except, as the early theorist of semiotics Charles Sanders Pierce suggests, at an instantaneous and inarticulable level: one can, Pierce says, 
experience, but not know, reality-in-itself. This is not to say that this experience of the real is not real; it is: we live in a real world. But we live particularly in our codification, our system of signs. If we cannot translate any experience into symbolic form then we cannot 'know' it in a way that is useful to us; if we do know, then our knowledge is only knowledge through our codes and our signifying systems--that is, mediated knowledge. (as when we might experience an earthquake without immediately knowing what it is, and so for a moment experience only something like disoriented panic).

All texts are mediated (are only the process of mediation), in many ways: they are mediated by language, they are mediated by cultural systems, including ideologies and symbols, they are mediated by the conventions of genres, they are mediated by the world of intertextuality which is textuality's only true home, they are mediated by the structure of ideas and practices which we call reading (there is no 'pure reading', there is only reading according to some tradition, for some purpose). Texts are mediated in their construction, in their communication, and in their reception. Texts cannot, by definition, simply transfer an author's ideas.

Our mediated knowledge works as all signs systems work, not by identification but by differences and through codes.

\section{Deconstruction assumptions}

In deconstruction the basic structuralist principle of difference is located ontologically as well as semiotically: at the very point of beingness of every thing there is difference -- or différance -- because only through différance is one thing not another thing instead. Différance comes before being; similarly, a trace comes before the presence of a thing (as anything which is is itself by virtue of not being something else, by differing, and that which it differs from remains as a trace, that whose absence is necessary for it to be); so too writing precedes speech -- a system of differences precedes any location of meaning in articulation. See my summary of Derrida, Différance.

Deconstruction, as do other poststructural theories, declines the structuralist assumption that structural principles are essences -- that there are universal structural principles of language which exist 'before' the incidence of language. (The emphasis on the concrete, historical and contingent in opposition to the eternalities of essence reveals one of deconstruction's filiations with existentialism.) All 'principles' of existence (i.e., of experience) are historically situated and are structured by the interplay of individual experience and 
institutional force, through the language, symbols, environment, exclusions and oppositions of the moment (and of the previous moments through which this one is constructed). Structures are historical, temporary, contingent, operating through differentiation and displacement.

There is no outside of the text; everything that we can know is text, that is, is constructed of signs in relationship. This claim does not mean that there is nothing outside of language: the claim refers to the realm of human knowledge, not to the realm of concrete existence (elusive as that might be). Deconstruction does not deny the existence of an independent, physical world.

All texts are constituted by difference from other texts (therefore similarity to them). Any text includes that which it excludes, and exists in its differences from/filiations with other texts.

Opposites are already united; they cannot be opposites otherwise. Nor can they be a unity, and be themselves. They are the alternating imprint of one another. There is no nihilism without logocentrism, no logocentrism without nihilism, no presence without absence, no absence without presence, and so forth.

Inherent in language itself is difference and deferral; it is impossible for language to be identical with its referents. A word or any other sign can only mobilize the play of the fields of signs from which it is distinguished, and from which it is of necessity removed. See quote from Barbara Johnson, below.

Inherent in language also is the contest between grammar and rhetoric. Grammar is the syntagmatic protocol, meaning as created by placement; rhetoric is the intertextual system of signs which makes what the grammar means, mean something else (irony and metaphor are principal examples). Grammatical and rhetorical meaning cannot be identical, and one may well not be able to assign a priority of 'meaning'.

In a sense deconstruction is profoundly historical: it sees temporality as intrinsic to meaning, in that meaning can only be structured against that which is before it, which is structured against that which is before that. Meaning is that which differs, and which defers. The claim is not that there is no meaning -- that is a misunderstanding of deconstruction: the claim is that what we take to be meaning is a shifting field of relations in which there is no stable point, in which dynamic opposing meanings may be present simultaneously, in which 
the meaning is textually modulated in a interweaving play of texts. Meaning circulates, it is always meaning by difference, by being other. The meaning-through-difference creates/draws on 'traces' or 'filiations', themselves in some senses historical.

Deconstruction is also historical insofar and it functions etymologically, turning to the root, often metaphorical, meanings of words for an understanding of how they function within the web of differentiation which spans the chasm of the non-human over which we constantly live.

as deconstruction works on (in both senses of 'works on') the web of differentiation which spans the chasm of the non-human over which we constantly live, it is intrinsically and deeply human and humane. It is affirmative of the multiplicity, the paradoxes, the richness and vibrancy, of our life as signifying beings. If it seems to deny affirmation, it is because it knows that affirmation is always, intimately and compellingly, itself, only in the presence of and by virtue of negation. To fully live we must embrace our deaths.

if deconstruction seems to oppose Humanism, it is because Humanism operates by substituting the concept 'man' for the concept 'God'(or 'order', 'nature', 'Truth', 'logos', etc.) and so placing 'man' as the unproblematic ground of meaningfulness for human life. It should be clear, however, that 'man' is then a hypothesized center, substituting for another hypothesized center, in the history of metaphysics. Deconstruction wants to clarify the instability upon which such a concept is grounded.

one can and indeed must work with ideas such as 'center', 'man', 'truth', but must work with them knowing their instability; to do so is, in deconstructive terms, to place them "under erasure." To signify this graphically, use the strikethrough option on your computer. That's the truth.

deconstructive reading can be applied to any text. It is a theory of reading, not a theory of literature. Derrida generally deconstructs philosophical writing, showing the metaphysical contradictions and the historicity of writing which lays claim to the absolute.

'literature' is a writing clearly open to deconstructive reading, as it relies so heavily on the multiple meanings of words, on exclusions, on substitutions, on intertextuality, on filiations among meanings and signs, on the play of meaning, on repetition (hence significant 
difference). In Jakobson's phrasing, literature attends to (or, reading as literature attends to), the poetic function of the text. This, in (one guesses) a Derridean understanding would mean that the naive, thetic, transcendental reading of a text is com-plicated (folded-with) by a counter-reading which de-constructs the thetic impetus and claims.

the more 'metaphysical' or universal and 'meaningful' a text the more powerfully it can provoke deconstructive reading; similarly as 'reading as literature' implies a raising of meaning to the highest level of universality, 'reading as literature' also calls forth the potential for a strong counter-reading. As Derrida says, "the more it is written, the more it shakes up its own limits or lets them be thought."

Some attributes of 'literature' in the deconstructive view are:

1. that literature is an institution, brought into being by legal, social and political processes;

2. that literature is that which at the same time speaks the heart of the individual and which shows how the individual is made possible only by otherness, exteriority, institution, law, structures and meanings outside oneself;

3. that literature is both (simultaneously) a singular, unrepeatable event and a generalizable experience, and demonstrates the tension/ antithesis between these -- as something which is original is also of necessity not original, or it could not have been thought.

It is possible that texts which 'confess' the highly mediated nature of our experience, texts which themselves throw the reader into the realm of complex, contested, symbolized, intertextual, interactive mediated experience, texts which therefore move closer than usual to deconstructing themselves, are in a sense closer to reality (that is, the truth of our real experience) than any other texts. This kind of text conforms to the kind of text known as 'literature' -- most clearly, to modernist literature, but to all texts which participate in one or more of the ironic, the playful, the explicitly intertextual, the explicitly symbolizing -- from Renaissance love poetry to Milton to Swift to Fielding to Tennyson to Ondaatje.

Reading these texts in the deconstructive mode is, however, not a matter of 'decoding the message'; it is a matter of entering into the thoughtful play of contradiction, multiple reference, and the ceaseless questioning of conclusions and responses. The less a text deconstructs 
itself, the more we can and must deconstruct it, that is, show the structures of thought and assumption which ground it and the exclusions which make its meaning possible. If, as Roman Jakobson suggests, a mark of literature is that it draws attention to its textuality, its constructedness, then literature may be said to be inherently closer to 'reality' than other forms of writing or discourse are, just when it seems to be furthest away, as our 'reality' is symbolic, signified, constructed.

The particular strategy of deconstructive reading is based on fissures in what we take to be the common-sense experience of texts and reality, and on reversals, oppositions and exclusions that are lying in wait in, or implicit in, signification and textuality. Take, for example, the sorts of conflict Jonathan Culler suggests in On Deconstruction that the critic is on the lookout for:

1. the asymetrical opposition or value-laden hierarchy (e.g. host and parasite, logocentrism and nihilism) in which one term is promoted at the expense of the other. The second term can be shown to constitute or signal the condition for the first, and the hierarchy up-turned (this is not a simple reversal, as the reversal is then in the condition of reversibility, and so forth).

2. points of condensation, where a single term brings together different lines of argument or sets of values (and hostilities to hosts hosting the Host).

3. The text will be examined for ways in which it suggests a difference from itself, interpretations which undermine the apparently primary interpretation.

4. figures of self-reference, when a text applies to something else a description, figure or image which can be read as a self-description, an image of its own operations. This opens up an examination of the stability and cogency of the text itself. An example of self-reference is in the vines and parasites in place of the erased (, i.e. under erasure) antique and learned imagery of Shelley's "Epipsychidion" in Miller's "The Critic as Host," the natural images themselves an image for and replacement for (every image of is also a replacement for) the tracing of writing, which is itself the writing that constitutes the poem; the images of the poem themselves attempt to naturalize what cannot be naturalized, writing itself, in a recuperation in which the act of naturalizing reveals itself as an ancient strategy of meaning, so the imagery is an image of itself. 
5. conflicting readings of a texts can be see as reenactments of conflicts within a text, so that readings can be read as partializing moves simplifying the complex interplay of potential meaning within the text.

6. Attention to the marginal, and that which supplements -as with hierarchized oppositions, the margin in fact encompasses or enables the rest, so that a marginalized figure, idea, etc. can be re-read as the 'center', or controlling element; similarly the supplement re-centers and re-orients that which it supplements, as the fact of supplementing reveals the inadequacy, the partiality/incompleteness of the supplemented item.

pp. $213-215$

The deconstructive activity is ceaseless. It can never be resolved in a dialectic (that is, there is no synthesis), 1 ) but is always reaching back to a pattern of operations, antitheses, displacements and so forth, each 'behind', or 'before', or logically, ontologically, referentially, hierarchically, temporally or semantically or etymologically, etc, 'prior to' the other, and 2) alternating between the poles of antitheses or opposite.

Like the form of mathematics called topography, deconstruction studies surfaces, as there are no depths, however firmly we may think we see them: there are only twists, (con)figurations, (re)visions. 